\title{
The Performance of US Marijuana Stocks
}

\author{
Raymond A. K. Cox \\ Thomson Rivers University \\ Quan Cheng
University of the Fraser Valley
}

This study examines the investment performance of US based marijuana stocks. Medical marijuana was first legalized in 1996 by the state of California. During the 1996 to 2020 period the 200 US marijuana stocks as a sector portfolio experienced high: mean weekly return, standard deviation, positive skewness, and kurtosis. Sensitivity analysis, to outliers, was conducted on the winsorized returns (removing the top and bottom 10 percent of returns) generated much the same results. More so, the US marijuana stock portfolio outperformed the NASDAQ, DJIA, and S\& P 500 stock indexes. Further, the portfolio beta was negative. Investors should consider including US marijuana stocks in their portfolio for both augmented return and risk diversification reasons.

Keywords: marijuana, cannabis, stocks, returns, investments, performance

\section{INTRODUCTION}

Since the beginning of time investors continue to be in search of superior performing investments. Superior investments are characterized by high returns and low risk. However, Fama $(1965,1970)$ posited the efficient markets hypothesis (EMH) showing the tradeoff between risk and return (Markowitz, 1952 and Sharpe, 1963, 1964) and how excess returns in the long run should not exist. Nevertheless, individuals, analysts, and money managers persevere to find superior investments.

A relatively new investment opportunity is marijuana stocks in the United States (US). Medical marijuana was first legalized in 1996 by the state of California. Subsequently, 41 additional states have legalized marijuana for medicinal purposes. Now, there are 17 US states where marijuana is fully legal and 32 states that have decriminalized violations of marijuana laws. See Appendix 1 for the legal status of marijuana in each US state.

A marijuana stock is where the firm produces, distributes, or sells cannabis (marijuana) products. This is a broad definition and includes non-cannabis products such as Guard-Ex (Grave, 2020). We examine 200 US marijuana stocks during 1996 to 2020 and find, on average, much higher returns compared to stock market benchmarks. 


\section{LITERATURE REVIEW}

In an efficient market all prices reflect all available information. As such, passive investment strategies that approximate holding the market portfolio proxied by a large broad stock market index should be effective (Malkiel, 2003). Nonetheless, Pastor and Stambaugh (2012) present a model on how active investment management can garner better returns. Numerous studies have validated active management styles such as value and growth (Petkova and Zhang, 2005); small cap (Allen, 2005); socially responsible (Mollett and Ziegler, 2014); and income (Divecha and Morse, 1983). Even so, stock market efficiency has changed over time (Lim and Brooks, 2011) be it weak form (Shynkevich, 2012), semi-strong form (Alexakis, Patra, and Poshakwale, 2010), or strong form (Chau and Vayanos, 2008).

The literature on marijuana (or cannabis) stocks is a sub-set of the investment category of sin stocks; also known as vice stocks, shunned stocks, controversial stocks, and unethical stocks (Blitz and Fabozzi, 2017). Firms focused on alcohol, gambling, tobacco, weapons, or porn are considered sin stocks. There is a body of empirical evidence that sin stocks provide significant positive returns. That is, investors earn a reputation risk premium. Investors require a higher return from sin stocks to compensate taking on these stocks of ill repute. Hence, the extra reputation risk premium over and above other risk premiums such as inflation risk and liquidity risk. Salaber (2007) studied 18 European countries for the 1975 to 2006 period. Sin stocks experienced higher returns attributed to a litigation risk premium. More so, countries were classified as Protestant or Catholic. In Protestant countries, as opposed to Catholic countries, sin stocks were subject to more lawsuits which resulted in higher required returns. Salaber (2009) examined 183 US sin stocks, monthly returns from 1926 to 2005, and found positive excess returns and some support for sin stock returns being counter-business cycle. Fabozzi, Ma, and Oliphant (2008) surveyed 21 countries during 1970 to 2007 and found positive abnormal returns for sin stocks. Both Hong and Kacperczyk (2009) and Statman and Glushkov (2009), with US only samples from 1965 to 2006 and 1992 to 2007 respectively, detected positive Jensen (1968) alphas from sin stocks. Blitz and Fabozzi (2017) studied a global sin stock sample from the 1963 to 2016 period. The results varied by geographic sector. In general, sin stocks generated a positive Jensen alpha and low beta.

Islam and Dar (2016) investigated specifically monthly returns of 21 US marijuana stocks from 2013 to 2017 showing them to outperform the Standard and Poor's 500 index (S \& P 500). Lu-Andrews (2017) looking at 28 OTC (over-the-counter) US stocks in 2016 (that year only) examined IPO (initial public offering) spillover effects of IIPR (Innovative Industrial Properties), a new Real Estate Investment Trust (REIT) with marijuana real estate facilities. The marijuana stocks experienced positive abnormal returns (market and risk-adjusted) during the announcement period and downsize period, and negative abnormal returns in the final completion period. This showed contagion effects outweighed competition effects during the announcement versus completion period. Weiskopf (2020) with 33 US cannabis stocks, 2014 to 2018 period, found positive abnormal returns. Andrikopoulos Gebka, and Kallinterakis (2020) studied the herding of 303 US and 156 Canadian cannabis stocks, 2011 to 2019. Herding is where the individual firm's stock returns in the industry move together. They discovered herding for Canadian cannabis stocks but no herding for US cannabis stocks.

\section{RESEARCH METHODOLOGY AND HYPOTHESES}

We select our sample from MarijuanaStocks.com, their list of marijuana stocks. The first marijuana stock, Acacia Diversified Holding Inc. (stock symbol ACCA), trading in the US on the OTC market beginning on February 5, 1996. We gather 1250 adjusted (for cash dividends, stock splits, and stock dividends) weekly stock prices from Yahoo Finance until January 6, 2020. We employ the jump method for missing price data. That is, the last known market price is the plug for a missing price until the next known (actual) share price. We calculate 1249 weekly returns by the holding period return (HPR) formula 1:

$R_{t}=\left(P_{t}-P_{t-1}\right) / P_{t-1}$ 
where $\mathrm{R}$ is the holding period return,

$\mathrm{P}$ is the share price,

$\mathrm{t}$ is the week.

The sample size is 200 US marijuana stocks across the 24-year period.

A US marijuana industry portfolio is formed on an equally-weighted basis by formula 2 :

$M P_{t}=\sum_{x=1}^{n} R_{t . x} / \mathrm{n}$

where $\mathrm{MP}_{\mathrm{t}}$ is the US marijuana portfolio return in week $\mathrm{t}$,

$\mathrm{R}_{\mathrm{t}, \mathrm{x}}$ is the stock return in week $\mathrm{t}$ for stock $\mathrm{x}$,

$\mathrm{n}$ is the total number of US marijuana stocks trading in week $\mathrm{t}$.

Initially there are few stocks in the industry portfolio. Not until March 8, 2010 is the US marijuana industry portfolio at the n-size of 20. Elton and Gruber (1977) indicated it is necessary to have 20 stocks in a diversified portfolio to eliminate $95 \%$ of unsystematic risk.

We hypothesize that US marijuana stocks on average and as an industry portfolio will earn high excess returns by formula 3 :

$E R_{n}=\sum_{t=1}^{n}\left(M P_{t}-B_{t}\right) / n$

where $\mathrm{ER}_{\mathrm{t}}$ is the excess mean return of the US marijuana portfolio across time $t$,

$\mathrm{MP}_{\mathrm{t}}$ is the weekly return of the US marijuana portfolio at time $t$,

$\mathrm{B}_{\mathrm{t}}$ is the weekly return of the stock market benchmark at time $\mathrm{t}$,

$\mathrm{n}$ is the number of weeks.

We employ 3 separate stock market benchmarks: (1) NASDAQ, (2) Dow Jones Industrial Average (DJIA), and (3) S \& P 500. We examine 2 time periods: (1) Complete time period, for all stocks in the sample, February 5, 1996 to January 6, 2020 (1249 weeks), and (2) 20 stocks or more time period, March 8, 2010 to January 6, 2020 (514 weeks).

We hypothesize that the US marijuana industry portfolio will have higher variability of return (standard deviation shown in formula 4) and lower covariance risk (beta from the capital asset pricing model- market model version displayed in formula 5).

$S D=\sum_{t=1}^{n}\left[\left(M P_{t}-R_{n}\right)^{2} /(n-1)\right]^{0.5}$

where SD is the standard deviation across the time-period,

$\mathrm{MP}_{\mathrm{t}}$ is the return in week $\mathrm{t}$ of the US marijuana industry portfolio,

$\mathrm{R}_{\mathrm{n}}$ is the mean weekly return for the time-period $\mathrm{n}$ weeks (i.e. $\sum_{t=1}^{n} M P_{t} / n$ ),

$\mathrm{n}$ is the number of weeks in the time-period.

A simple linear regression is run to compute the alpha and beta of each stock and the industry portfolio. Note, this is not the Jensen alpha. The industry portfolio is expressed in formula 5:

$M P_{t}=\alpha_{P}+\beta_{P} I_{t}$

where $\mathrm{MP}_{\mathrm{t}}$ is the return in week $\mathrm{t}$ of the US marijuana industry portfolio,

$I_{t}$ is the return in week $\mathrm{t}$ of the stock market index benchmark,

$\alpha_{P}$ is the alpha (intercept) of the US marijuana industry portfolio,

$\beta_{P}$ is the beta of the US marijuana industry portfolio. 
We report the skewness (formula 6) and kurtosis (formula 7) statistics:

Skewness $=\sum_{i=1}^{T}\left(x_{i}-\bar{x}\right)^{3} /(n-1) \cdot s^{3}$

Kurtosis $=\sum_{i=1}^{T}\left(x_{i}-\bar{x}\right)^{4} /(n-1) \cdot s^{4}$

where $\mathrm{S}$ is the $\mathrm{SD}$ (standard deviation)

\section{RESULTS}

Descriptive statistics are reported in Table 1 for the 2 US marijuana stock portfolios of: (1) All Stocks from 1996 to 2020, and (2) 20 + Stocks from 2010 to 2020. In addition, the descriptive statistics are described for each of the 3 stock market benchmarks (NASDAQ, DJIA, and S \& P 500). Observing Table 1 , in both time periods the US marijuana industry portfolio clearly generates (in decimal form for weekly returns) high mean return ( 0.157128 for 1996 to 2020, and 0.214110 for 2010 to 2020), standard deviation (1.494706 for 1996 to 2020, and 2.116227 for 2010 to 2020), skewness (25.161823 for 1996 to 2020, and 20.600001 for 2010 to 2020), and kurtosis (750.232626 for 1996 to 2020, and 448.474531 for 2010 to 2020) when compared to the 3 benchmarks.

TABLE 1

\section{DESCRIPTIVE STATISTICS}

\begin{tabular}{|ccccc|}
\hline \multicolumn{5}{c|}{ All Stocks 1996 - 2020 } \\
\hline Portfolio & NASDAQ & DJIA & S\&P 500 \\
\hline Mean & 0.157128 & 0.002211 & 0.001586 & 0.001566 \\
STD DEV & 1.494706 & 0.031710 & 0.022974 & 0.023673 \\
Skewness & 25.161823 & -0.576506 & -0.599115 & -0.517926 \\
Kurtosis & 750.232626 & 5.986928 & 5.513650 & 5.153830 \\
\hline
\end{tabular}

\begin{tabular}{|ccccc|}
\hline \multicolumn{5}{c|}{ 20+ Stocks $\mathbf{2 0 1 0} \mathbf{- 2 0 2 0}$} \\
\hline Portfolio & NASDAQ & DJIA & S\&P 500 \\
\hline Mean & 0.214110 & 0.002915 & 0.002124 & 0.002230 \\
STD DEV & 2.116227 & 0.022383 & 0.018703 & 0.019238 \\
Skewness & 20.600001 & -0.546315 & -0.433208 & -0.502667 \\
Kurtosis & 448.474531 & 1.641525 & 1.683954 & 1.967656 \\
\hline
\end{tabular}

Many of the stocks have low prices, some less than a penny (USD 0.01) per share, causing large spikes (both positive and negative) in returns for relatively small absolute price changes. To mitigate the possible distortion on the performance results we winsorise both portfolios by eliminating the bottom and top 10 percent of returns. The results for the winsorised returns are given in Table 2. The all-stock-portfolio (1996 to 2020) mean return increases to 0.19211 whereas the 20+ stocks portfolio (2010 to 2020) declines substantially to 0.034307 . Otherwise, there is a decline in the standard deviation to 0.59762 (1996 to 2020) and 0.054507 (2010 to 2020), skewness to 0.790485 (1996 to 2020) and 1.018972 (2010 to 2020), and kurtosis to 0.298611 (1996 to 2020) and 0.632452 (2010 to 2020). 
TABLE 2

WINSORISED - ALL STOCKS 1996 - 2020

\begin{tabular}{|ccrrr|}
\hline & Portfolio & \multicolumn{1}{c|}{ NASDAQ } & \multicolumn{1}{c|}{ DJIA } & \multicolumn{1}{c|}{ S\&P 500 } \\
\hline Mean & 0.19211 & 0.002211 & 0.001586 & 0.001566 \\
STD DEV & 0.59762 & 0.031710 & 0.022974 & 0.023673 \\
Skewness & 0.790485 & -0.576506 & -0.599115 & -0.517926 \\
Kurtosis & 0.298611 & 5.986928 & 5.513650 & 5.153830 \\
\hline
\end{tabular}

WINSORISED - 20+ STOCKS 2010-2020

\begin{tabular}{|ccrrr|}
\hline & Portfolio & \multicolumn{1}{c|}{ NASDAQ } & \multicolumn{1}{c|}{ DJIA } & \multicolumn{1}{c|}{ S\&P500 } \\
\hline Mean & 0.034307 & 0.002915 & 0.002124 & 0.002230 \\
STD DEV & 0.054507 & 0.022383 & 0.018703 & 0.019238 \\
Skewness & 1.018972 & -0.546315 & -0.433208 & -0.502667 \\
Kurtosis & 0.632452 & 1.641525 & 1.683954 & 1.967656 \\
\hline
\end{tabular}

Table 3 presents the market-adjusted excess returns computed for each of the 3 benchmarks. Panel A shows the outcome for the total sample. Regardless of the benchmark and no matter which of the 2 time periods the excess returns are strongly positive. The excess returns in the 1996 to 2020 period compared to the NASDAQ, DJIA, and S \& P 500 are 0.15387, 0.154804, and 0.154628 respectively and for 2010 to 2020 the excess returns versus the same 3 benchmarks are $0.211193,0.211984$, and 0.211878 respectively. The winsorised samples continue to produce positive excess returns, especially for the latter time period, as presented in Panel B. During the 1996 to 2020 time period the excess returns compared to the NASDAQ, DJIA, and S \& P 500 are $0.002211,0.001586$, and 0.001566 respectively. For the 2010 to 2020 period the excess returns are $0.031392,0.032183$, and 0.032077 compared to each of the same 3 benchmarks.

The results of the alpha and beta estimates is presented in Table 4. The beta for all-stocks (1996 to 2020 ) is -0.300373 and for $20+$ stocks (2010 to 2020) is -3.341462 . US marijuana stocks are negatively correlated with return movements in the stock market. This makes for ample diversification benefits to include US marijuana stocks in investor's portfolio. Another approach to investing in US marijuana stocks is as a contrarian strategy in a bear market. That is, as the stock market, as a whole, declines the US marijuana industry portfolio will move in the opposite direction.

TABLE 3

EXCESS RETURNS

\begin{tabular}{|cccc|}
\hline \multicolumn{4}{|c|}{ PANEL A - TOTAL SAMPLE } \\
Based on Benchmark & NASDAQ & DJIA & S\&P 500 \\
All Stocks 1996-2020 & 0.153870 & 0.154804 & 0.154628 \\
20+ Stocks 2010-2020 & 0.211193 & 0.211987 & 0.211878 \\
\hline \multicolumn{4}{|c}{ PANEL B - WINSORISED SAMPLE } \\
\hline Based on Benchmark & NASDAQ & DJIA & S\&P 500 \\
All Stocks 1996-2020 & 0.002211 & 0.001586 & 0.001566 \\
20+ Stocks 2010-2020 & 0.031392 & 0.032183 & 0.032077 \\
\hline
\end{tabular}




\section{TABLE 4 \\ CAPITAL ASSET PRICING MODEL - MARKET MODEL NADDAQ STOCK MARKET BENCHMARK}

\begin{tabular}{|ccc|}
\hline US Marijuana Portfolio & Alpha & Beta \\
$\mathbf{1 9 9 6}$ to 2020 & 0.157791 & -0.300373 \\
$\mathbf{2 0 1 0}$ to 2020 & 0.224150 & -0.341462 \\
\hline
\end{tabular}

\section{CONCLUSIONS}

We find investing in a portfolio of US stocks in the marijuana (cannabis) sector during 1996 to 2020 outperformed the NASDAQ, DJIA, and S \& P 500 indexes. Also, a portfolio of these stocks provided a significant diversification benefit due to a negative beta. Nevertheless, this portfolio experienced great risk based on a huge standard deviation, skewness, and kurtosis. Investing in US marijuana stocks is not for the faint-hearted along with the caveat that past results do not portend future results.

\section{REFERENCES}

Allen, G.C. (2005). The Active Management Premium in Small-Cap US Equities. Journal of Portfolio Management, 31(3), 10-17. https://doi.org/10.3905/jpm.2005.500348

Alexakis, C., Patra, T., \& Poshakwale, S. (2010). Predictability of Stock Returns Using Financial Statement Information: Evidence on Semi-Strong Form Efficiency of Emerging Greek Market. Applied Financial Economics, 20(16), 1321-1326. https://doi.org/10.1080/09603107.2010.482517

Andrikopoulos, P., Gebka, B., \& Kallinterakis, V. (2019). How 'High' on Herding are Cannabis Stocks? https://doi.org/10.2139/ssrn.3508297

Blitz, D., \& Fabozzi, F.J. (2017). Sin Stocks Revisited: Resolving the Sin Stock Anomaly. Journal of Portfolio Management, 44(1), 105-111. https://doi.org/10.3905/jpm.2017.44.1.105

Chau, M., \& Vayanos, D. (2008). Strong-form efficiency with monopolistic insiders. Review of Financial Studies, 21(5), 2275-2306. https://doi.org/10.1093/rfs/hhl029

Divech, A., \& Morse, D. (1983). Market Responses to Dividend Increases and Changes in Payout Ratios. Journal of Financial and Quantitative Analysis, 18(2), 163-173. https://doi.org/10.2307/2330915

Elton, E.J., \& Gruber, M.J. (1977, October). Reduction and Portfolio Size: An Analytic Solution. Journal of Business, 50, 415-437. https://doi.org/10.1086/295964

Fabozzi, F.J., Ma, K.C., \& Oliphant, B.J. (2008). Sin Stock Return. Journal of Portfolio Management, 35(1), 82-94. https://doi.org/10.3905/JPM.2008.35.1.82

Fama, E.F. (1965). The Behavior of Stock Market Prices. Journal of Business, 38(1), 34-105. https://doi.org/10.1086/294743

Fama, E.F. (1970). Efficient Capital Markets: A Review of Theory and Empirical Work. Journal of Finance, 25(2), 383-417. https://doi.org/10.2307/2325486

Gravill, J. (2020). The Race in the Cannabis Screening Device Industry: Will Guard-Ex be a Winner? Journal of Applied Business and Economics, 22(14), 12-22. https://doi.org/10.33423/jabe.v22i14.3962

Hong, H., \& Kacperczyk, M. (2009). The Price of Sin: The Effect of Social Norms on Markets. Journal of Financial Economics, 93(1), 15-36. https://doi.org/10.1016/j.jfineco.2008.09.001

Islam, A., \& Dar, A.A. (2016). The Stock that Outperforms Not Only Minds But Also Markets: The Marijuana Stock. Funoon: An International Journal of Multidisciplinary Research, 2(1), 1-12. Retrieved from https://www.researchgate.net/profile/Ajaz-Islam2/publication/289673572_The_Stock_that_Outperforms 
_Not_Only_Minds_But_Also_Markets_The_Marijuana_Stock/links/5c3de54aa6fdccd6b5aee591/ The-Stock-that-Outperforms-Not-Only-Minds-But-Also-Markets-The-Marijuana-Stock.pdf

Jensen, M.C. (1968). The Performance of Mutual Funds in the Period 1945-1964. Journal of Finance, 23, 389-416. https://doi.org/10.1111/j.1540-6261.1968.tb00815.x

Lim, K.P., \& Brooks, R. (2011). The Evolution of Stock Market Efficiency over Time: A survey of the Empirical Literature. Journal of Economic Surveys, 25(1), 69-108. https://doi.org/10.1111/j.1467-6419.2009.00611.x

Lu-Andrews, R. (2018). IPO Spillover Effects in a New and Uncertain Sector: The Case of a Marijuana REIT. Journal of Management Policy and Practice, 19(3), 147-169. https://doi.org/10.33423/jmpp.v19i3.54

Malkiel, B.G. (2003). Passive Investment Strategies and Efficient Markets. European Financial Management, 9(1), 1-20. https://doi.org/10.1111/1468-036X.00205

Markowitz, H. (192). Portfolio Selection. Journal of Finance, 7(1), 77-91. https://doi.org/10.1111/j.15406261.1952.tb01525.x

Mollet, J.C., \& Ziegler, A. (2014). Socially Responsible Investing and Stock Performance: New Empirical Evidence for the US and European Stock Markets. Review of Financial Economics, 23(4), 208-216. https://doi.org/10.1016/j.rfe.2014.08.003

Petkova, R., \& Zhang, L. (2005). Is Value Risker than Growth? Journal of Financial Economics, 78(1), 187-202. https://doi.org/10.1016/j.jfineco.2004.12.001

Pastor, L., \& Stambaugh, R.F. (2012). On the Size of the Active Management Industry. Journal of Political Economy, 120(4), 740-781. https://doi.org/10.1086/667987

Sharpe, W. (1963). A simplified Model for Portfolio Analysis. Management Science, 9, 277-293. https://doi.org/10.1287/mnsc.9.2.277

Sharpe, W. (1964). Capital Asset Prices: A Theory of Market Equilibrium Under Conditional Risk. Journal of Finance, 19(3), 425-442. https://doi.org/10.1111/j.1540-6261.1964.tb02865.x

Salaber, J.M. (2007). The Determinants of Sin Stock Returns: Evidence on the European Market. DRM: Publications, Universite Paris-Dauphine. https://doi.org/10.2139/ssrn.1071746

Salaber, J.M. (2009). Sin Stock Returns Over the Business Cycle. http://dx.doi.org/10.2139/ssrn.1443188

Statman, M., \& Glushkov, D. (2009). The Wages of Social Responsibility. Financial Analysts Journal, 65(4), 33-46. https://doi.org/10.2469/faj.v65.n4.5

Shynkevich, A. (2012). Performance of Technical Analysis in Growth and Small Cap Segments of the US Equity Market. Journal of Banking and Finance, 36(1), 193-208. https://doi.org/10.1016/j.jbankfin.2011.07.001

Weisskopf, J-P. (2020, March). Breaking Bad: An Investment in Cannabis. Finance Research Letters, 33. https://doi.org/10.1016/j.frl.2019.05.019

\section{APPENDIX}

LEGAL STATUS OF MARIJUANA BY US STATE

\begin{tabular}{|c|c|c|c|}
\hline State & Legal Status & Medicinal & Decriminalized \\
\hline Alabama & Fully Illegal & No & No \\
\hline Alaska & Fully Legal & Yes & Yes \\
\hline Arizona & Fully Legal & Yes & Yes \\
\hline Arkansas & Fully Legal & Yes & Yes \\
\hline California & Fully Legal & Yes & Yes \\
\hline Colorado & Fully Legal & Yes & Yes \\
\hline Connecticut & Mixed & Yes & Yes \\
\hline Delaware & Mixed & Yes & No \\
\hline District of Columbia & Fully Legal & Yes & Yes \\
\hline Florida & Mixed & &
\end{tabular}




\begin{tabular}{|c|c|c|c|}
\hline Georgia & Mixed & CBD Oil Only & No \\
\hline Hawaii & Mixed & Yes & Yes \\
\hline Idaho & Fully Illegal & No & No \\
\hline Illinois & Fully Legal & Yes & Yes \\
\hline Indiana & Mixed & CBD Oil Only & No \\
\hline Iowa & Mixed & CBD Oil Only & No \\
\hline Kansas & Fully Illegal & No & No \\
\hline Kentucky & Mixed & CBD Oil Only & No \\
\hline Louisiana & Mixed & Yes & No \\
\hline Maine & Fully Legal & Yes & Yes \\
\hline Maryland & Mixed & Yes & Yes \\
\hline Massachusetts & Fully Legal & Yes & Yes \\
\hline Michigan & Fully Legal & Yes & Yes \\
\hline Minnesota & Mixed & Yes & Yes \\
\hline Mississippi & Mixed & Yes & Yes \\
\hline Missouri & Mixed & Yes & Yes \\
\hline Montana & Fully Legal & Yes & Yes \\
\hline Nebraska & Fully Illegal & Yes & No \\
\hline Nevada & Fully Legal & Yes & Yes \\
\hline New Hampshire & Mixed & Yes & Yes \\
\hline New Jersey & Fully Legal & Yes & Yes \\
\hline New Mexico & Mixed & Yes & Yes \\
\hline New York & Fully Legal & Yes & Yes \\
\hline North Carolina & Fully Illegal & No & Yes \\
\hline North Dakota & Mixed & Yes & Yes \\
\hline Ohio & Mixed & Yes & Yes \\
\hline Oklahoma & Mixed & Yes & No \\
\hline Oregon & Fully Legal & Yes & Yes \\
\hline Pennsylvania & Mixed & Yes & No \\
\hline Rhode Island & Mixed & Yes & Yes \\
\hline South Carolina & Fully Illegal & No & No \\
\hline South Dakota & Fully Legal & Yes & Yes \\
\hline Tennessee & Fully Illegal & No & No \\
\hline Texas & Mixed & CBD Oil Only & No \\
\hline Utah & Mixed & Yes & No \\
\hline Vermont & Fully Legal & Yes & Yes \\
\hline Virginia & Mixed & CBD Oil Only & Yes \\
\hline Washington & Fully Legal & Yes & Yes \\
\hline West Virginia & Mixed & Yes & No \\
\hline Wisconsin & Mixed & CBD Oil Only & No \\
\hline Wyoming & Fully Illegal & No & No \\
\hline
\end{tabular}

